\title{
TIRS: SMS based Transportation Information Retrieval System
}

\author{
Vijay Kumar Katiyar, Ph.D \\ Department of Computer Science and Engineering, \\ MMEC, Maharishi Markandeshwar University, \\ Mullana, Haryana, India-133207
}

\author{
Dalip Kamboj \\ Department of Information Technology, \\ MMEC, Maharishi Markandeshwar University, \\ Mullana, Haryana, India-133207
}

\begin{abstract}
This GPS and SMS based system provides real time navigational information of transportation along with a database for analysis of vehicle movement. Besides multiple common features with other similar systems it has a unique feature for estimating expected arrival time based on history of movement. This system is applicable on transportations like car, truck, bike, rail and bus etc. TIRS is also an open access tool via internet or SMS for its users for decision making to save time, money and selection of best route. With SMS and internet users it has a good business potential. This system implements on two transportation mode like fuel tanker and buses.
\end{abstract}

\section{Keywords}

GPS, SMS, TIRS, Navigational, Transportation mode, Emulator.

\section{INTRODUCTION}

Transportation is movement of animals, goods and people from one location to another. There are several modes of transportation like road, rail, air, water and space. Traffic congestion is [1] increasing on both rail and road transport networks throughout world and scope to build additional network capacity is limited in terms of land availability and expense. Research indicates that providing more road space leads to further demand, which in turn reduces capacity and increases congestion. So some new methods are required for managing the efficient use of rail and road networks and operation of the existing infrastructure. The first earth tracks were created by humans carrying goods and often followed game trails. Tracks would be naturally created at points of high traffic density. Several animals became essentials in track creation like horses, oxen and donkeys were domesticated.

SMS- also known as [2] Short Messaging Service or text messaging-is a feature available on all mobile phones which allows a small amount of text to be sent between one user and another. There are several applications of SMS: Person-toPerson Text Messaging, Marketing, Remote System Monitoring, Stock Market Alerts, E-Commerce and Credit Card Transaction Alerts, Email, Fax and Voice Message Notifications and Provision of Information.

The Global Positioning System (GPS) is a satellite navigation system that provides [3] location and time information in all weather conditions, anywhere on or near the Earth where there is an unobstructed line of sight to four or more GPS satellites. For GPS receiver minimum four satellites are required. The system provides critical capabilities to military, civil and comer bcial users around the world. It is maintained by the United States government. If ignore the cost of GPS device then it is freely accessible to everyone. Wireless technologies such as GPRS, new 3G, 4G networks and different WLAN technologies are rapidly being developed [4] and deployed providing wireless access to the Internet in a much larger scale than before. At the same time, new mobile platforms like PDAs, advanced mobile phones and wearable computers are becoming more and more common. Together it will mean that the Internet will be accessible from anywhere, on a wide variety of different platforms and connection technologies. Fig 1 shows the traffic congestion picture. Traffic congestion result when more vehicles available on road. It may occur on any road system. More chances of traffic congestion are during the starting and ending session of companies and industries.

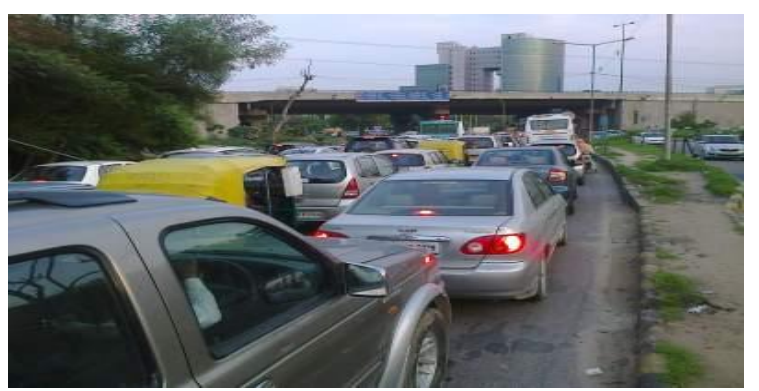

Fig 1: Traffic congestion

There are the several drawbacks in existing travelling systems of transportation. The main problem is face by passengers in buses. Even users know the buses schedule well, there are many reasons buses are not coming at estimated time. Traffic congestion, buses crashes, accidents and many other problems faced by bus organizations can delay and disrupt the buses service. During interviews, exam and emergencies situation we face lot of problems due to bus late. An unexpected bus arrival time has given us inspiration for developing the TIRS bus system. Unique feature of propose system estimate the expected arrival time on the basis of navigational history of vehicle. This navigational history is stored in database. Propose system is very help full on those routes where filling stations are 20 kilometers far away from each others. During the time of journey if vehicle has very low fuel and it enough for travel 15-20 kilometers only. In this situation rider will decide to go near by filling station. It may be possible filling station has either less fuel or no fuel. Next filling station is 20 kilometers far away from current station. On this time what should do? With the help of TIRS system station master see the arrival time of fuel tanker. If fuel tanker arrives at next 510 minutes, then rider can easily decided he should wait. But 
if arrival time is larger than he should be go for another option.

The rest of the paper as follow: The Section II provides the information about related work and motivation. The section III describes proposed system detail. The section IV describes the impact, usefulness and preplanning. The section VI describes the results of the paper. The section VII describes the conclusion and future work of the paper.

\section{RELATED WORK AND MOTIVATION}

As mentioned in the introduction the there are the several applications based on SMS. Now day most of peoples use the SMS for accessing the information, because its cost is low. SMS based system are used in various areas which are given below. Banking: Mobile phone banking has the potential to extend financial services through virtual accounts to millions of poor people globally. Utilizing [5] mobile phone technology for microfinance extensively lowers transaction costs, while increasing outreach to rural areas. Change is being driven by falling costs of mobile phones including airtime, by competition and by the ability of electronic banking solutions to offer customers an enhanced range of services at a very low cost. Text-a-payment (TAP) builds upon the familiarity and comfort that people around the world have with sending text messages (or SMS) via their mobile phone. Instead of traveling to the bank to make their loan payment, clients can now text their loan payment directly to the bank; saving them both travel time and money. This is also helpful for the bank, since it can enlarge its outreach to rural areas while reducing its costs. With SMS alert service customer receive transaction statues like debit and credit money from their account. Final Examination: This system is SMS based for conducting final examination. Currently, each semester [6] there are around 5000 students enrolled in various courses offered by the universities. This means that on the average 200 to 300 students will take an examination in a single session per day throughout the 20 to 30 days of the final examination exercise. Earthquake: The Earthquake disaster gave rise to an unprecedented use of information systems (IS). In addition humanitarian workers had to cope with a massive amount of information received through web portals, platforms, and social networking media, such as SMS feeds, Facebook, Twitter [7]. To help process the SMS messages, volunteers located all over the world were solicited to translate them and put them into the required SAHANA format. The Thomson Reuters Foundation [8] offered a free Emergency IS, providing users with practical and reliable information. This system also makes information available to subscribers via phone SMS. Health Monitoring and Transportation: In health monitoring and transportations [9] lot of applications already have been developed and using in real life. For example Mobile Energy Balance (PmEB) mobile phone application that allows users to self-monitor caloric balance in real time with the help of mobile phone SMS. Next bus and Waitless bus tracking systems are existing transportation system which provides the exact information of buses on real time bases. Some transportation systems provide the vehicle location information with SMS.

Most of the passengers are often late to job interview because they waste many time to decide whether they wait for bus or walking. Existing transportation information systems are very costly and not provide reliable service to user. So this system is developed with advance feature which is reliable and less costly.

\section{PROPOSED SYSTEM DETAIL}

\subsection{Transportation Mode}

Man and animals are also mean of transportation. The information of the transportation retrieved with the help of GPS device. GPS device received the signals from the satellites. It connected with mobile tower and continuously sends SMS to server.

\subsection{SMS Information Storage Area}

This area stored all information about vehicle like vehicle id, route information, stops etc. Administrator is the main person who has the main control over this area. Server contains the databases. The data base contains several tables, vehicle type, Route, stops and vehicle position etc. These contains several types of information like vehicle type, vehicle ID, vehicle type, Arrival time, Departure time, vehicle speed and Vehicle location etc.

\subsection{Hardware and Software}

For this application mainly two softwares are required Arcmaps and ArcGIS. ArcMap users can create and manipulate data sets to include a variety of information. For example, the maps created in ArcMap [10] generally consist of features such as north arrows, scale bars, titles, legends, etc. The software packages consist of style-set of these features. The ArcGIS suite is available at three license levels: Basic, Standard, or Advanced (formerly ArcView, ArcEditor, or ArcInfo). The hardware requirements are GPS module, Mobile phones, GPRS, Laptop/ Desktop pc, Bluetooth device. 


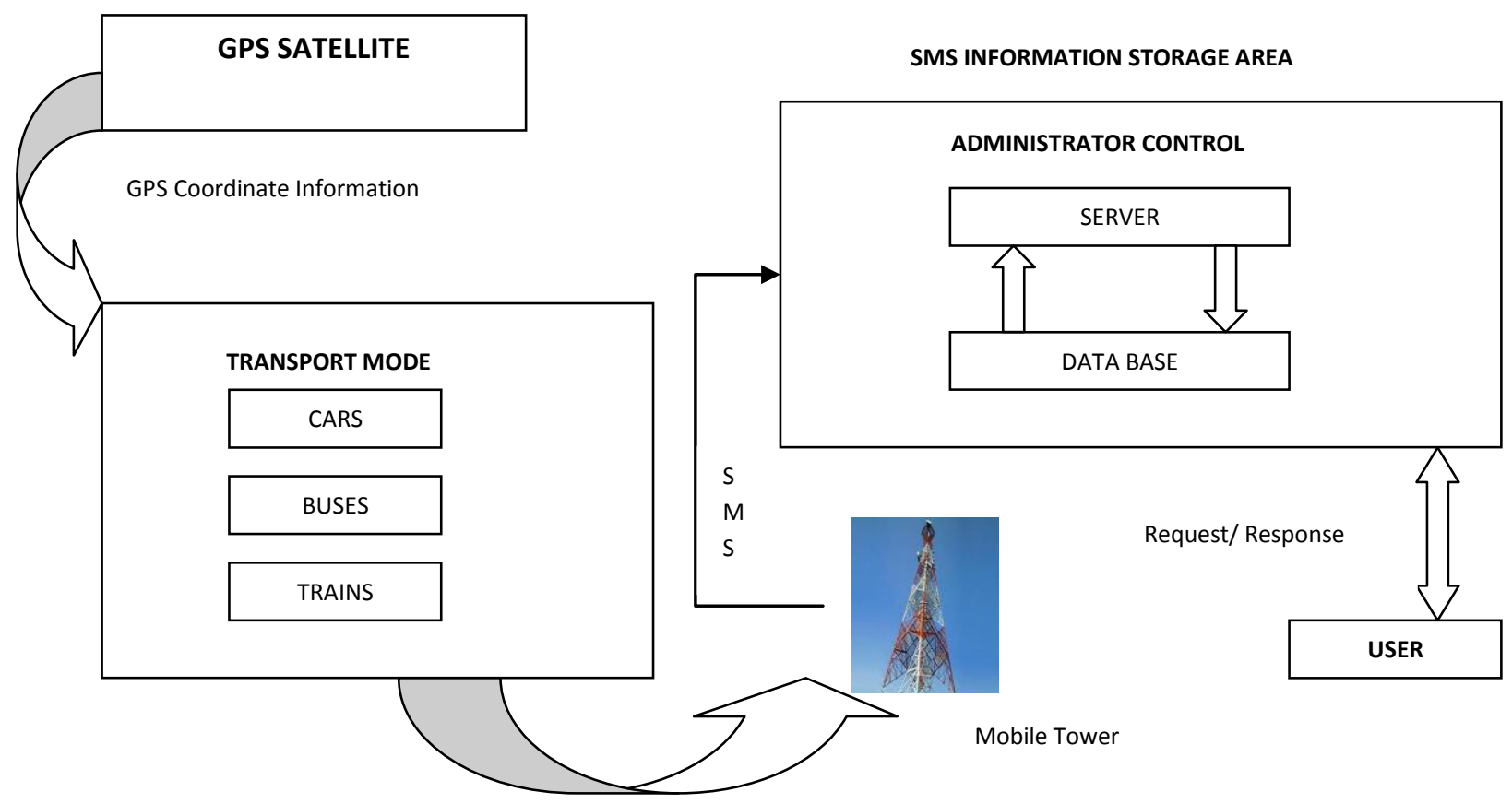

Fig 2: Overview of TIRS system

Fig 2 shows the proposed architecture of TIRS system. This system is applicable on public and private organization. Transportation modes received the GPS coordinate information with GPS module. The SMS information storage areas contain all the vehicle navigation information. This area is control by the administrator. If user wants to access the information about any particular vehicle then it sends the message to server. Server processes the user request and searches the relevant information from database. If information is found into the database then server sends the response to user.

\subsection{Sequence Diagram of Proposed System}

Fig 3 shows the sequence diagram of proposed system. For this diagram three objects are: User, Sever and Data base. User or passenger wants to receive the information about particular vehicle. Into the given figure user send SMS to server with the help of mobile device, server is connected to database. After receiving SMS server first view the type of request and then process it. Sever send the request to data base. All navigational information of vehicle stored in Database. Database search the relevant information and send response back to server. Finally sever send SMS to user.

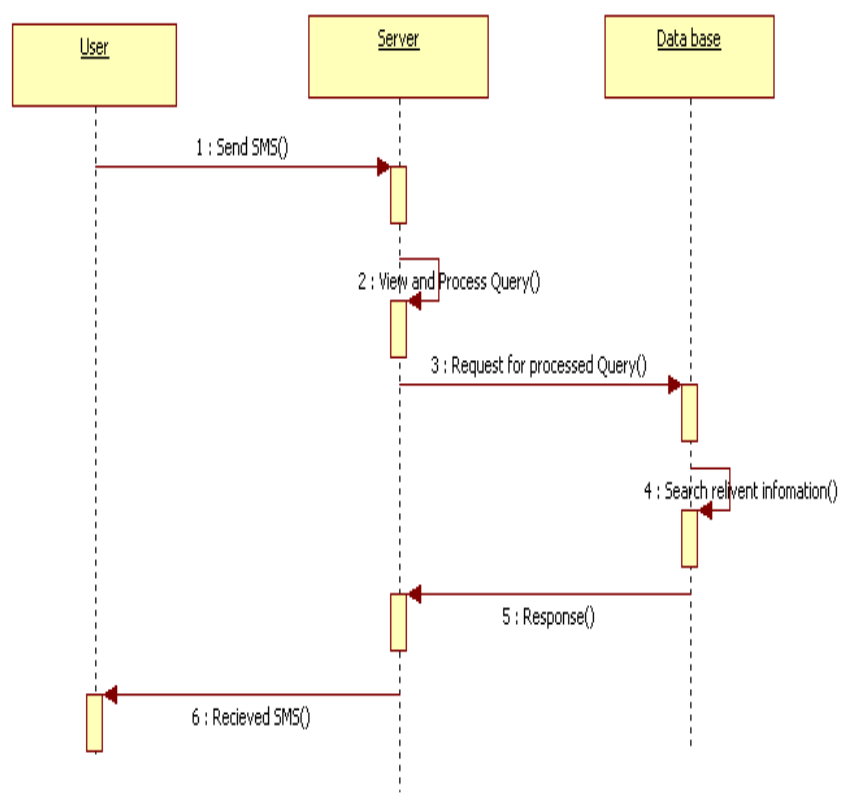

Fig 3: Sequence diagram for information retrieval 


\section{PROCEDURE FOR IMPLEMENT- ATION}

There are the following steps involved for implementing the TIRS system. In to the first step requirements analysis and Information gathering analysis the state of current SMS information system for the transportation and the current technology used for information retrieval. Which software's and hardware devices are required for implementing the system? How to provide the maximum satisfaction to passengers. One main issue is the financial cost of the system. The cost of the system should not be large. For this system the information is collected from the various transportation organizations. Prototype of the system shows overall architecture of system. The information storage area is the main component of TIRS, because it contains all information about transportation modes. Considered all the technical and functional aspect at the time of create prototype. In implementation phase implements the TIRS in real time. For real implementation many software and hardware devices are required. In testing and evaluation phase detect the errors from the system and evaluate the performance of the system. In final stage installed proposed system at broad level.

\section{PRIMPACT, USEFULNESS AND PREPLANNING}

With improving the information technology information retrieval is very easy about transportation for Educational organizations. Many educational organizations have more than hundred buses. Users for educational organizations are students, staff and parents etc. Users can access navigational information of vehicles with SMS. Now a lot of research is running on public and private transportation. Today everyone is busy in own life. So people have no time to wait at stops. So, with the help of TIRS system users can access the vehicle navigational information without waiting. This system is useful for both user and owner of system. From business point of view SMS charges are earning money for owner of system.

Passengers must be preplanned before starting his/ her journey. At first passenger decide where he/she wants to go, how many times are required in travelling, when the bus will arrive. Passenger should be confirmed the departure time of bus. So that, passenger will wait at the bus stop without any prior notice of bus arrival time. The bus may arrive on schedule or it may arrive later than the expected time due to some external factors. The last stage obviously is the arrival of the bus regardless the buses arrive on time or arrive late to that particular bus stop. On that time a question arise in passenger mind what he/she should do on that time.

\section{RESULTS}

The main interface between the user and TIRS system is mobile SMS interface. This system will allow TIRS system to receive SMS request from mobile users, process the SMS request and response with relevant information via SMS. All these functionality are done by SMS module. If the users want to get vehicle information then he will need to follow some predefined instruction in order so that TIRS system easily understand users request and give successfully response. The predefined instructions are vehicle Id, route name, stop name. After received this predefined instructions server will give response in the form of SMS. Sever gives this type of navigational information like name of desired stop, next stop arrival time, total travelling time. The given fig 4 and fig 5 shows the vehicle information on emulator and mobile device with current status. Results on emulator show simulation and result on mobile device shows reality. Sample data is taken from Indian transportation for experimental results. Table1 contains the navigational information of Indian transportation. Proposed system provides the navigational information of all possible alternate routes for single route. For e.g. Yamuna Nagar to Delhi route has three possible alternate routes via indri, pipli and kurukshetra. Given table shows various routes. Unique feature of this system provides the next stops arrival time. For pages other than the first page, start at the top of the page, and continue in double-column format. The two columns on the last page should be as close to equal length as possible.

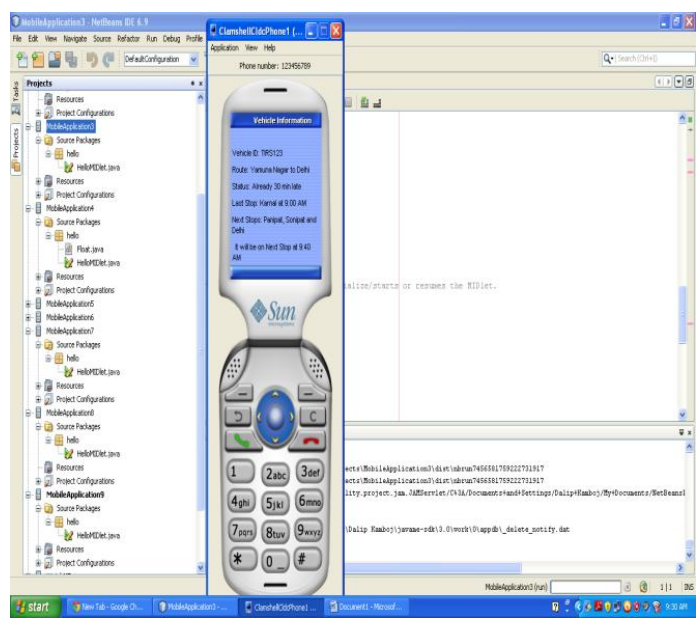

Fig 4: Vehicle information on Emulator

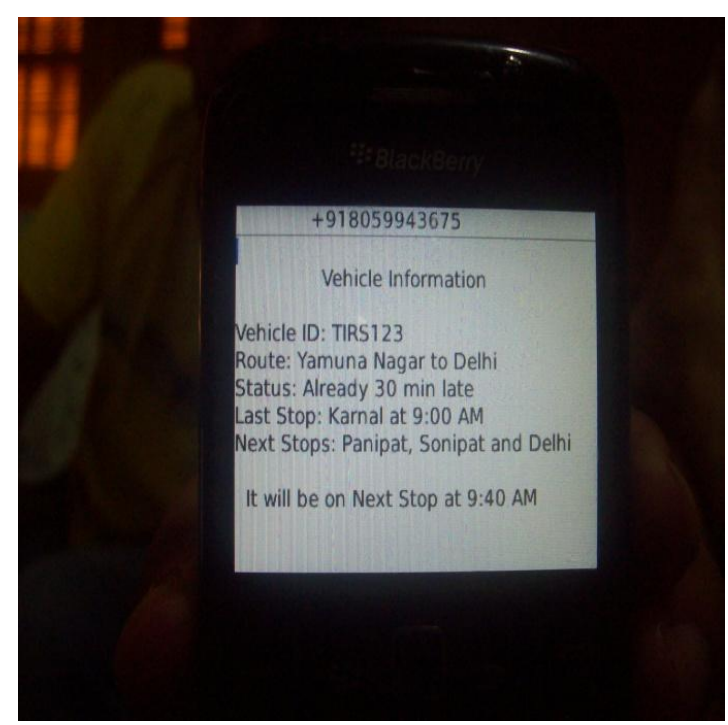

Fig 5: Vehicle information on Mobile Device 
Table 1. Route wise vehicle navigational information

\begin{tabular}{|c|c|c|c|c|c|c|c|c|}
\hline $\begin{array}{l}\text { Vehicle } \\
\text { ID }\end{array}$ & Route & Source & $\begin{array}{l}\text { Destinatio } \\
\mathbf{n}\end{array}$ & Stops & $\begin{array}{l}\text { Estimate } \\
\text { d Time }\end{array}$ & $\begin{array}{l}\text { Arriva } \\
\text { I Time }\end{array}$ & $\begin{array}{l}\text { Statu } \\
\text { S }\end{array}$ & Next Stop \\
\hline $\begin{array}{l}\text { HR1300 } \\
1\end{array}$ & $\begin{array}{l}\text { Yamuna } \\
\text { Nagar to } \\
\text { Delhi }\end{array}$ & $\begin{array}{l}\text { Yamuna } \\
\text { Nagar }\end{array}$ & Delhi & Radaur & 5:00 AM & $\begin{array}{l}5: 10 \\
\text { AM }\end{array}$ & $\begin{array}{l}10 \\
\min \\
\text { late }\end{array}$ & $\begin{array}{l}\text { Will be on } 5: 30 \\
\text { AM }\end{array}$ \\
\hline $\begin{array}{l}\text { HR1300 } \\
7\end{array}$ & $\begin{array}{l}\text { Delhi to } \\
\text { Yamuna } \\
\text { Nagar }\end{array}$ & Delhi & $\begin{array}{l}\text { Yamuna } \\
\text { Nagar }\end{array}$ & Karnal & 1:00 PM & $\begin{array}{l}1: 00 \\
\text { PM }\end{array}$ & $\begin{array}{l}\text { On } \\
\text { time }\end{array}$ & $\begin{array}{l}\text { Will be on } \\
1: 50 \text { PM }\end{array}$ \\
\hline $\begin{array}{l}\text { HR1300 } \\
5\end{array}$ & $\begin{array}{l}\text { Yamuna } \\
\text { Nagar to } \\
\text { Delhi }\end{array}$ & $\begin{array}{l}\text { Yamuna } \\
\text { Nagar }\end{array}$ & Delhi & Panipat & 5:30 PM & $\begin{array}{l}\text { 6:00 } \\
\text { PM }\end{array}$ & $\begin{array}{l}30 \\
\text { min } \\
\text { late }\end{array}$ & $\begin{array}{l}\text { Will be on } 6: 40 \\
\text { PM }\end{array}$ \\
\hline $\begin{array}{l}\text { HR1300 } \\
8\end{array}$ & $\begin{array}{l}\text { Ambala to } \\
\text { Chandig- } \\
\text { arh }\end{array}$ & $\begin{array}{l}\text { Ambala } \\
\text { Cantt }\end{array}$ & $\begin{array}{l}\text { Chandigar } \\
\mathrm{h}\end{array}$ & $\begin{array}{l}\text { Zirakpu } \\
r\end{array}$ & 10:35 AM & $\begin{array}{l}10: 35 \\
\text { AM }\end{array}$ & $\begin{array}{l}\text { On } \\
\text { time }\end{array}$ & $\begin{array}{l}\text { Will be on } \\
\text { 10:50 AM }\end{array}$ \\
\hline $\begin{array}{l}\text { HR1300 } \\
3\end{array}$ & $\begin{array}{l}\text { Kuruksh- } \\
\text { etra to } \\
\text { Panchkua }\end{array}$ & $\begin{array}{l}\text { Kurukshet } \\
\text { ra }\end{array}$ & Panchkula & Saha & 2:00 PM & $\begin{array}{l}2: 10 \\
\text { PM }\end{array}$ & $\begin{array}{l}10 \\
\text { min } \\
\text { late }\end{array}$ & $\begin{array}{l}\text { Will be on 2:40 } \\
\text { PM }\end{array}$ \\
\hline
\end{tabular}

\section{CONCLUSION AND FUTURE WORK}

Today life is very fast, so everyone busy. So that TIRS is very help full for those people. TIRS provide information quickly, just send SMS by users. This system provides the real time location for each transportation mode. Without knowledge of arrival time of vehicle passengers waste lot of time in decision making (either they wait or go). This system is also helpful in case of emergencies situations. In future it will also be a part of more intelligent systems. It reduces the travelling time, transportation cost and congestion. It increases safety, efficiency and reliability. With improvements in GPS technology accuracy of system can be improves and minimizes errors.

\section{REFERENCES}

[1] Dr. Paul E. Firmin, "Satellite Navigational Technology Application for Intelligent Transportation System: A European Prespective", Paper No. 70 presented at the European Navigation Conference - Manchester $8^{\text {th }}-10^{\text {th }}$ May 2006.

[2] SMS Quick Start Guide, "Changemakers Ashoka innovators for the public", Arilington, VA 22209-1929 USA. www.changemakers.com

[3] http://en.wikipedia.org/wiki/Global_Positioning_System

[4] Roland Parviainen and Peter Parnes," Mobile Instant Messaging”, 0-7803-7661-7/03/\$17.00@ 2003 IEEE.

[5] John Owens and Anna Bantug- Herrera, “ Catching the Technology Wave: Mobile Phone Banking and Text-aPayment in Philippines", Chemonics International Inc. Washington.

[6] http://www.academia.edu/1380571/SMS

[7] Julie Dugdale, Bartel Van de Walle and Corinna Koeppinghoff," Social Media and SMS in the Haiti
Earthquake", WWW 2012 Companion, April 16-20, 2012, Lyon, France. ACM 978-1-4503-1230-1/12/04.

[8] Reuters. 2010, Haiti wants more information on foreign aid, http://www.reuters.com/article/2010/03/03/usquake-haitieu idUSTRE6225UO20100303 Retrieved Aug 6, 2011.

[9] C. C. Tsai, G. Lee, F. Raab, G. J. Norman, T. Sohn, W. G. Griswold and K. Patrick, "Usability and feasibility of PmEB: A mobile phone application for monitoring real time caloric balance", Springer, Mobile Network Application. 2007. Vol 12, pp 173-184.

[10] http://en.wikipedia.org/wiki/ArcMap

\section{AUTHORS' PROFILES}

Prof. (Dr.) Vijay Kumar Katiyar born in Kanpur, India, on 30th June 1972. He received his Ph.D degree from M. M. University Mullana and B.E \& M.E. degrees from Kumaon University Nainital (U.P) and Thapar University Patiala (Punjab) respectively. He has supervised $22 \mathrm{M}$. Tech and 1 M. Phil candidates. His research interests are in Wireless Sensor Networks, Reliability Theory and Artificial Neural Networks, etc. He has about 16 years experience in teaching. $\mathrm{He}$ is also a member of IEEE. He has published about 20 research papers in international journals of repute. Presently he is supervising $8 \mathrm{Ph}$. D and $10 \mathrm{M}$. Tech candidates.

Dalip Kamboj is currently pursuing regular Ph.D from Markandeshwar University Mullana, Ambala, Haryana. He is Research Scholar in Information Technology department. He received Graduation Degree from Kurukshetra University, Haryana, in 2006, MCA degree from Kurukshetra University in 2009 and M.Tech. degree from M. M. University Mullana in 2011. He is University Topper in Ph.D course work and Gold Medalist in M.Tech. He has number of publications in International journals/Conferences to his credit. His current research interest includes Intelligent Transportation Systems, MANETs, Wireless communications and Pervasive Computing/ Ubiquitous Computing etc. 